\title{
Synthesis of a DOPO-triazine additive and its flame-retardant effect in rigid polyurethane foam
}

https://doi.org/10.1515/epoly-2019-0024

Received October 30, 2018; accepted November 30, 2018.

Abstract: A DOPO (9,10-dihydro-9-oxa-10-phosphaphenanthrene-10-oxide)-based halogen-free flame retardant (ODOPM-CYC) was synthesized and incorporated in rigid polyurethane foam (RPUF). The structure of ODOPM-CYC was characterized by Fourier transform infrared spectra (FTIR), ${ }^{1} \mathrm{H}$ NMR and ${ }^{31} \mathrm{P}$ NMR. The effects of ODOPMCYC on the flame resistance, mechanical performances, thermal properties and cell structure of RPUF were also investigated. The results showed that the incorporation of ODOPM-CYC strikingly enhanced flame retardant properties of RPUF. The flame retarded RPUF acquired a limiting oxygen index (LOI) value of $26 \%$ and achieved UL-94 V-0 rating with the phosphorus content of $3 \mathrm{wt} \%$. The smoke production rate (SPR) also showed an obvious decrease and total smoke release (TSR) was 39.8\% lower than that of neat RPUF. Besides, the results demonstrated that the incorporation of ODOPM-CYC provided RPUF better thermal stability but did not show any obvious influence on its thermal conductivity.

Keywords: flame retardant; ODOPM-CYC; RPUF; thermal stability; mechanical properties

\section{Introduction}

As an excellent polymeric material of great versatility, RPUF has been widely used in many fields, including cushions, sealants, aeronautics, and astronautics. Notably, taking the advantage of the ultra-low thermal conductivity (0.018$0.028 \mathrm{~W} \mathrm{~m}^{-1} \mathrm{~K}^{-1}$ ) and high mechanical properties, RPUFs are commonly used as the insulation materials in buildings (1).

\footnotetext{
* Corresponding author: Lin Liu, School of Materials Science and Engineering, and Institute for Advanced Study, Tongji University, 4800 Caoan Road, Shanghai 201804, China, e-mail: llsp@tongji.edu.cn. Rui Lv, School of Materials Science and Engineering, and Institute for Advanced Study, Tongji University, 4800 Caoan Road, Shanghai 201804, China.
}

However, the high flammability of RPUFs is a real threat to human life security, which greatly restricts its practical application. Once on fire, the produced toxic smokes may result in the great loss of economic risks and human lives. Therefore, the flame retardancy of RPUF, of necessity, needs to be improved to meet the strict standard of some established regulations for construction or transportation safety such as Final Draft prEN 13501-1 (2,3).

In recent years, a variety of flame retardants have been developed to improve the flame resistance of RPUF, including halogen-based materials, inorganic hydroxyl systems and phosphorus $(\mathrm{P})$ or nitrogen $(\mathrm{N})$ containing compounds, etc. (4-6). Among all classes of the retardants, halogen-based retardants, although efficient, have been restricted in certain applications due to the toxicity of the released smokes or gases towards surrounding environment and human health. On the basis of this point, various newstyle flame retardants with satisfactory efficiency have been developed (7-9). For example, Jin et al. have synthesized a lignosulfonate/ammonium polyphosphate-based RPUF, which endowed a great thermal stability and ultrahigh char yield (10). Wen and co-workers have reported a one-pot RPUF with expandable graphite and aluminum hypophosphite as the flame retardant, which exhibited an excellent synergistic effect on flame retardancy (11). However, the additional amount for the reported retardant is usually high and the overall materials' mechanical properties are always sacrificed. Therefore, it is of great significance for the preparation of efficient, less-doped and environmentally-friendly flame retardants.

DOPO (9,10-dihydro-9-oxa-10-phosphaphenanth-rene10-oxide) is a new type of phosphorus-containing flame retardant intermediate with limited toxicity, from which numerous functional derivatives can be obtained (12-15). Owing to the appealing inherent thermal and chemical stability caused by their main aromatic structures, DOPO and its derivatives have attracted large quantities of attentions for the application of efficient flame retardants in many inflammable materials (epoxy resins (16-19), polyester $(20,21)$, and flexible polyurethane foams (22-24), etc.) (25). For example, König et al. reported a new phosphorus flame retardant (methyl-DOPO), which 
showed an efficient flame retarding working mechanism in the gas phase when applied into flexible polyurethane foams (26). In addition, Cai and his co-workers synthesized a DOPO-based oligomer and incorporated it in epoxy resin, which achieved the LOI value of $35.3 \%$ and V-0 rating in VL-94 test with the addition amount of only $7 \mathrm{wt} \%$ (27). Recent reports have showed that DOPO and its derivatives suppress fire by releasing some low molecular weight phosphorous containing species, which are able to scavenge the $\cdot \mathrm{H}$ and $\cdot \mathrm{OH}$ radicals in fire (28). Besides, it has also been reported that the flame retardant efficiency would be significantly enhanced by the co-incorporation of both phosphorus and nitrogen (29-31). However, there are only limited reports on N, P-co-incorporated DOPO derivatives and its usage as flame retardants in RPUF.

In this work, a halogen-free phosphorus-nitrogen containing flame retardant (denoted as ODOPM-CYC) was successfully synthesized and used as the flame retardant in RPUFs. Flame retarded RPUFs with different contents of ODOPM-CYC were prepared and the fire behaviors were investigated via the LOI, vertical burning test (UL-94), and cone calorimeter testing. The thermal properties were determined by thermogravimetric analysis (TGA). Meanwhile, the effects of addition on the overall mechanical performances, morphological properties and thermal conductivities of foams were investigated by mechanical property measurement, scanning electron microscopic (SEM) and thermal conductivity analyzer, respectively.

\section{Experimental}

\subsection{Materials}

Polymethylene polyphenylene isocyanate (WANNATE PM-200, 30.5-32.0 NCO\%) and polyether polyol (Wanefoam

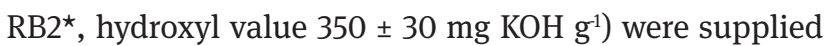
by Wanhua Chemical Group Co., Ltd. DOPO (9,10-dihydro9-oxa-10-phosphaphenanthrene-10-oxide, 97\%) was provided by Meryer (Shanghai) Chemical Technology Co., Ltd. Paraformaldehyde (AR) and cyanuric chloride (99\%) were obtained from Aladdin Reagents (Shanghai) Co., Ltd. Xylene, 1,4-dioxane, triethylamine were of analytical grade and purchased from Sinopharm Chemical Reagent Co., Ltd.

\subsection{Synthesis of ODOPM}

The ODOPM was prepared according to the previous report (32), which was shown in Scheme 1.

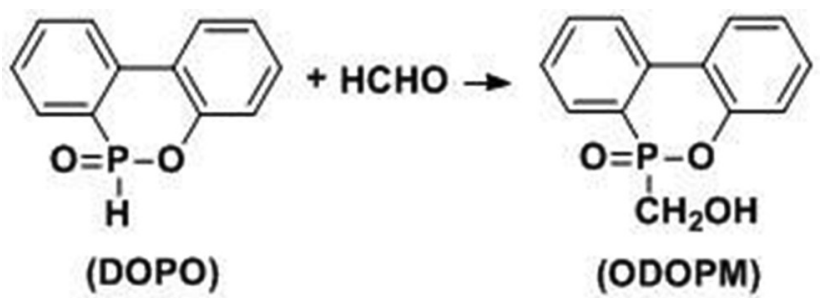

Scheme 1: Synthesis of ODOPM.

A three-necked round bottom flask $(500 \mathrm{~mL})$ equipped with a reflux condenser was charged with DOPO (21.6 g, $0.10 \mathrm{~mol})$ and xylene $(120 \mathrm{~mL})$. Then the mixture was heated to $90^{\circ} \mathrm{C}$ under nitrogen atmosphere and stirred until DOPO was dissolved completely. After that, paraformaldehyde $(3.0 \mathrm{~g}, 0.10 \mathrm{~mol})$ was added in batches for over $2 \mathrm{~h}$. The reaction mixture was heated to $135^{\circ} \mathrm{C}$ after the completion of paraformaldehyde addition and refluxed for another $6 \mathrm{~h}$. After cooled to the room temperature, the white precipitation was filtered and washed three times by xylene. The powdery product was dried at $60^{\circ} \mathrm{C}$ under vacuum to a constant weight. The yield of ODOPM was $97.6 \%$.

\subsection{Synthesis of ODOPM-CYC}

At first, ODOPM (36.9 g, $0.15 \mathrm{~mol}$, dissolved in $200 \mathrm{~mL}$ 1,4-dioxane) was added in a $500 \mathrm{~mL}$ three-necked round bottom flask equipped with a nitrogen inlet and a reflux condenser. Then cyanuric chloride $(9.225 \mathrm{~g}, 0.05 \mathrm{~mol}$, dissolved in $50 \mathrm{~mL}$ of 1,4-dioxane) was added into the above-mentioned solution and stirred for over $2 \mathrm{~h}$. After that, triethylamine $(15.18 \mathrm{~g}, 0.15 \mathrm{~mol})$ was added dropwise in three portions. After the addition of the first two portions, the reaction mixture was stirred at room temperature and $50^{\circ} \mathrm{C}$ for $3 \mathrm{~h}$, respectively. When the last addition completed, the mixture was further heated at reflux temperature for another $10 \mathrm{~h}$. Afterwards, the mixture was filtered while hot and the filtrate was distilled through rotary evaporator to remove 1,4-dioxane before dried at $80^{\circ} \mathrm{C}$ to a constant weight. The reaction process was illustrated in Scheme 2.

\subsection{Foam preparation}

The RPUF samples were prepared by one-pot free-rise method. PM-200 and polyether polyol were dried at $70^{\circ} \mathrm{C}$ for $12 \mathrm{~h}$ before using. The phosphorus content of the RPUF was fixed to $1 \mathrm{wt} \%$ and $4 \mathrm{wt} \%$, respectively.

The flame retardant was first mixed and dispersed in polyether polyol. Subsequently, PM-200 was added 


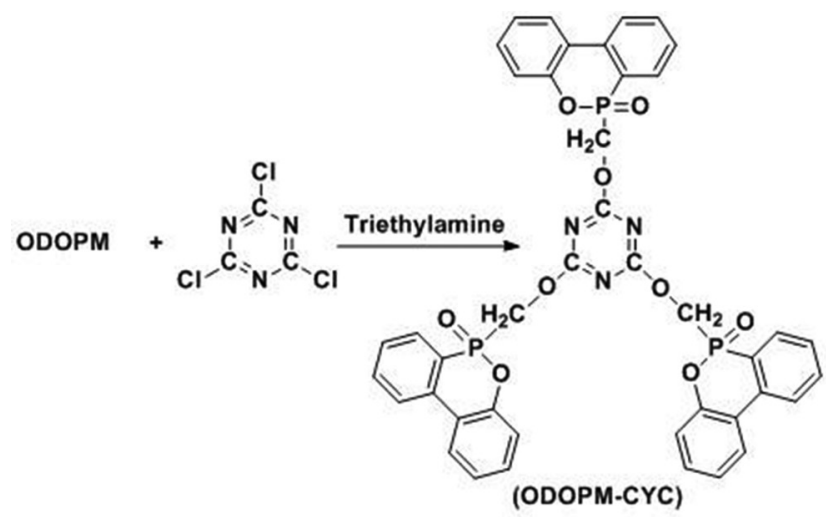

Scheme 2: Synthesis of ODOPM-CYC.

and stirred vigorously at $1800 \mathrm{rpm}$ for $10 \mathrm{~s}$. Then the mixture was quickly poured into an open mold $(150 \times 150$ $\times 100 \mathrm{~mm}^{3}$ ) to obtain a free-rise foam. Finally, the foam was placed in an oven for $24 \mathrm{~h}$ at $80^{\circ} \mathrm{C}$ to complete the polymerization reaction.

\subsection{Characterization}

The chemical structure of ODOPM and ODOPM-CYC were characterized by Fourier transform infrared (FTIR) spectra along with ${ }^{1} \mathrm{H}$ and ${ }^{31} \mathrm{P}$ nuclear magnetic resonance $\left({ }^{1} \mathrm{H}\right.$ NMR, ${ }^{31} \mathrm{P}$ NMR) spectroscopy. FTIR spectra were obtained using an EQUNOX55 spectrometer with the range of wavenumber from $500 \mathrm{~cm}^{-1}$ to $4000 \mathrm{~cm}^{-1}$ at room temperature using $\mathrm{KBr}$ pellets. The ${ }^{1} \mathrm{H}$ NMR and ${ }^{31} \mathrm{P}$ NMR analyses were performed on an AVANCE III NMR spectrometer at $300 \mathrm{MHz}$ and the samples were dissolved in DMSO- $d_{6}$.

LOI was obtained at room temperature by an oxygen index instrument (HC-2, Jiangning Analysis Instrument Company) with samples measurement of $100 \times 10 \times 10 \mathrm{~mm}^{3}$. UL-94 burning tests were performed on a vertical testing apparatus (CZF-3, Jiangning Analysis Instrument Company). The specimens for measurement were cut to a size of $100 \times$ $25 \times 13 \mathrm{~mm}^{3}$.

Cone calorimetry (CONE) was performed using a commercial cone calorimeter (FTT2000, FTT company, UK) with specimens exposed to a heat flux of $35 \mathrm{~kW} \mathrm{~m}^{-2}$. The size of the specimen was $100 \times 100 \times 20 \mathrm{~mm}^{3}$.

The thermal stability of the foams was carried out by a thermal analyzer (STD Q600) and the temperature was scanned from room temperature to $800^{\circ} \mathrm{C}$ with a heating rate of $10^{\circ} \mathrm{C} \mathrm{min}^{-1}$ under nitrogen atmosphere.

The compression strength and flexural strength were measured by a universal mechanical tester (SANS7 CMT-5105). The compression test was carried out with compression rate of $2 \mathrm{~mm} \mathrm{~min}^{-1}$ and specimens size of $20 \times 20 \times 20 \mathrm{~mm}^{3}$. All samples were run in quintuplicate and the average value was reported. The size of flexural strength tests specimen was $120 \times 25 \times 20 \mathrm{~mm}^{3}$ and the crosshead speed was $10 \mathrm{~mm} \mathrm{~min}^{-1}$. All samples were run in triplicate and the average value was reported.

The morphology of the foams were observed by scanning electron microscopy (SEM, Nova Nano SEM 450) at an accelerating voltage of $10 \mathrm{kV}$. The specimens were gold-coated with a conductive layer before test.

Thermal conductivities of the foams were measured using a thermal conductivity analyzer (DHR-II, Xiangtan Xiangyi Instrument Company). The size of the specimen was $100 \times 100 \times 20 \mathrm{~mm}^{3}$.

\section{Results and discussion}

\subsection{Characterization of ODOPM and ODOPM-CYC}

The chemical structure of ODOPM-CYC was characterized by FTIR, ${ }^{1} \mathrm{H}$ NMR and ${ }^{31} \mathrm{P}$ NMR (presented in Figure 1).

As seen from the FTIR spectra of ODOPM-CYC (Figure 1a), the absorption peaks at 1555, 1508, 1374 and $1360 \mathrm{~cm}^{-1}$ were attributed to the stretching vibration absorption of triazine ring skeleton (33,34). The absorption peaks at 1280 and $956 \mathrm{~cm}^{-1}$ belonged to the stretching vibration of $\mathrm{P}=\mathrm{O}$ and $\mathrm{P}-\mathrm{O}-\mathrm{Ph}$, respectively. In contrast to DOPO, the characteristic band for $\mathrm{P}-\mathrm{H}$ stretching vibration of OPOPM at $2438 \mathrm{~cm}^{-1}$ disappeared completely, while a new absorption peak at $3220 \mathrm{~cm}^{-1}$ for - $\mathrm{OH}$ appeared, suggesting that ODOPM was successfully produced during this feasible process. In addition, the absorption peaks at $3220 \mathrm{~cm}^{-1}$ disappeared in ODOPM-CYC, which might be ascribed to the successful reaction of OPOPM with cyanuric chloride.

The structures of ODOPM and ODOPM-CYC were further confirmed by ${ }^{1} \mathrm{H}$ NMR and ${ }^{31} \mathrm{P}$ NMR. As shown in Figure 1b, the peaks at 7.0-8.2 ppm were attributed to the Ar-H protons. Compared to the pure DOPO, the peak at $8.8 \mathrm{ppm}$, which was attributed to the proton of $\mathrm{P}-\mathrm{H}$, disappeared in ODOPM. The brand-new signals at 4.1 and $4.3 \mathrm{ppm}$ might be assigned to $-\mathrm{CH}_{2}$ - protons. Meanwhile, the shifting value of $5.6 \mathrm{ppm}$ for ODOPM was attributed to the proton of $-\mathrm{OH}(31,35)$. And the single peak at $5.6 \mathrm{ppm}$ disappeared in the spectrum of ODOPM-CYC, together with the signals of $-\mathrm{CH}_{2}-$ shifted to 4.9 and $5.1 \mathrm{ppm}$, indicating the reaction between ODOPM and cyanuric chloride. Correspondingly, the ${ }^{31} \mathrm{P}$ NMR spectra (Figure 1c) showed that the single peak in ODOPM at $33.6 \mathrm{ppm}$ shifted to $28.7 \mathrm{ppm}$ in ODOPM-CYC. These results indicated that ODOPM-CYC was successfully synthesized. 


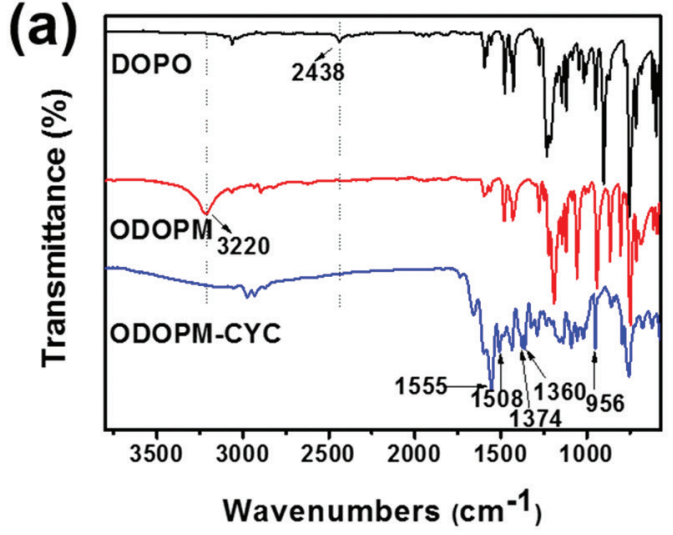

(b)

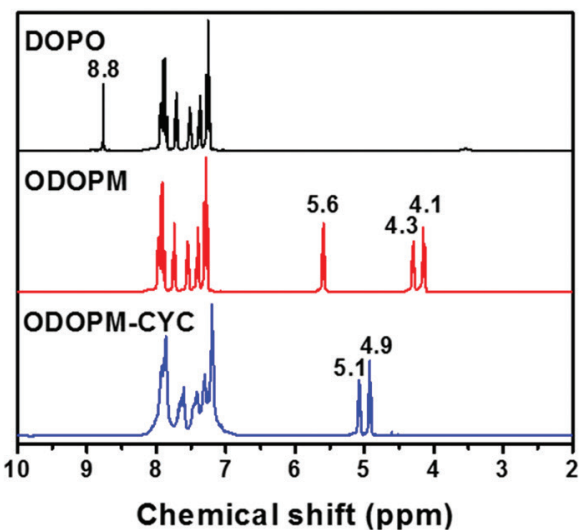

(c)

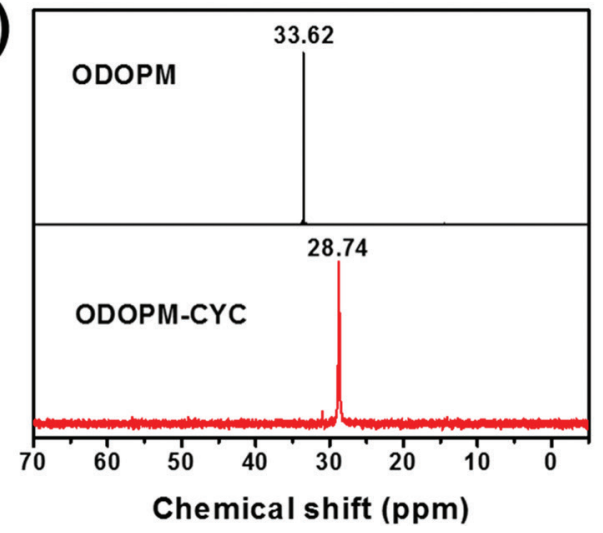

Figure 1: FTIR spectra (a) and ${ }^{1} \mathrm{H} N M R(b)$ of DOPO, ODOPM and ODOPM-CYC; (c) ${ }^{31}$ P NMR spectra of ODOPM and ODOPM-CYC.

\subsection{Characterization of flame retarded RPUFs}

\subsubsection{Fire behavior}

In order to evaluate the flame retardance of ODOPMCYC in RPUF, the LOI and UL-94 test results of RPUFs with different $\mathrm{P}$ mass ratios were listed in Table 1. For neat RPUF, the LOI value was only $18.5 \%$ and it failed to pass the UL-94 test. However, the LOI values showed continuous increase upon the increasing $\mathrm{P}$ content with the incorporation of ODOPM-CYC and the final RPUF containing ODOPM-CYC satisfied the $\mathrm{V}-0$ rating with a low P content of only $3.5 \mathrm{wt} \%$. Therefore, ODOPM-CYC was able to be recognized as an efficient flame retardant for RPUF. The remarkable increase of flame retardancy was mainly related to the existence of the inbuilt melamine structural unit in ODOPM-CYC. And the incorporation of nitrogencontaining group in DOPO compounds might achieved synergistic effect of phosphorus and nitrogen groups (30).

CONE has been widely used to evaluate the burning performance of materials in real fires and the testing results were summarized in Table 2. It can be found that the time to ignition (TTI) values of RPUFs containing ODOPM-CYC increased obviously, indicating that the presence of ODOPM-CYC delayed the ignition of foam and hindered the combustion process. The heat release rate (HRR) is commonly used for predicting the scale of flame propagation. The peak heat release rate (PHRR) usually represents the point where heat is likely to propagate or ignite adjacent objects in a fire. For flame retarded RPUF, the PHRR was 151.19 and $145.52 \mathrm{~kW} \mathrm{~m}^{-2}$ with 3 and $3.5 \mathrm{wt} \%$ $\mathrm{P}$, which was reduced by 31.2 and $33.8 \%$ than that of neat RPUF, respectively. This promising results were mainly due to the formation of intumescent char in flame retarded RPUF which performed as a barrier and obstructed the heat and mass transportation (36). Figure 2 displayed the digital photos of the residual neat RPUF and flame retarded RPUFs after CONE tests. It could be seen that obvious intumescent char was formed in the samples containing ODOPM-CYC. The total heat release (THR) for neat and flame retarded RPUFs were shown in Figure 3a. The THR of flame retarded RPUF with 3 and 3.5 wt $\%$ P was observed to be decreased by 13.0 and $24.0 \%$, respectively, indicating that the heat transfer and flame spread were hindered.

As we know, suffocation due to the inhalation of excess smokes is a major cause of casualties in fire accidents. Therefore, the reducing of SPR and TSR is of great necessity. As presented in Figure 3b, compared with neat RPUF, the two peaks of SPR were greatly suppressed in RPUFs containing ODOPM-CYC and the first peak of SPR was postponed from $10 \mathrm{~s}$ to $20 \mathrm{~s}$ with $\mathrm{P}$ content of $3.5 \mathrm{wt} \%$. Correspondingly, the peak of SPR values for flame retarded RPUF with 3 and $3.5 \mathrm{wt} \% \mathrm{P}$ decreased from 0.069 to 0.040 and $0.034 \mathrm{~m}^{2} \mathrm{~s}^{-1}$.

The TSR values (Figure 3c) were 197.57 and $197.89 \mathrm{~m}^{2} \mathrm{~m}^{-2}$, respectively, which were significantly lower than that of neat RPUF $\left(328.44 \mathrm{~m}^{2} \mathrm{~m}^{-2}\right)$. The smoke suppression was mainly due to the successful formation of the char layer, which prevented inner matrix from further degradation and fewer smokes were released (37). The char residue value (shown in Table 2) increased from 18.96\% (neat RPUF) 
Table 1: Formula and density, thermal conductivity, LOI, UL-94 results of RPUFs.

\begin{tabular}{|c|c|c|c|c|c|}
\hline Sample & $\begin{array}{r}\text { P content } \\
(w t \%)\end{array}$ & $\begin{array}{l}\text { LOI } \\
\text { (\%) }\end{array}$ & $\begin{array}{l}\text { UL-94 } \\
\text { rating }\end{array}$ & $\begin{array}{l}\text { Density } \\
\left(\mathrm{kg} \mathrm{m}^{-3}\right)\end{array}$ & 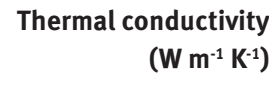 \\
\hline $\mathrm{F}_{\text {Blank }}$ & 0 & 18.5 & Fail & 34.5 & 0.0238 \\
\hline $\mathrm{F}_{1 \%}$ & 1 & 21.5 & Fail & 35 & 0.0238 \\
\hline $\mathrm{F}_{1.5 \%}$ & 1.5 & 22.5 & $V-2$ & 35 & 0.0237 \\
\hline $\mathrm{F}_{2 \%}$ & 2 & 23 & $\mathrm{~V}-1$ & 36 & 0.0238 \\
\hline $\mathrm{F}_{2.5 \%}$ & 2.5 & 24 & $\mathrm{~V}-1$ & 35 & 0.0239 \\
\hline $\mathrm{F}_{3 \%}$ & 3 & 25 & $V-1$ & 36 & 0.0238 \\
\hline $\mathrm{F}_{3.5 \%}$ & 3.5 & 26 & $\mathrm{~V}-0$ & 37 & 0.0240 \\
\hline $\mathrm{F}_{4 \%}$ & 4 & 26.5 & $\mathrm{~V}-0$ & 37 & 0.0241 \\
\hline
\end{tabular}

Table 2: Cone calorimetry testing data for RPUFs.

\begin{tabular}{|c|c|c|c|c|c|c|c|}
\hline Sample & TTI (s) & PHRR $\left(k W ~ m^{-2}\right)$ & THR (MJ m²) & $\begin{array}{r}\text { TSR } \\
\left(m^{2} m^{-2}\right)\end{array}$ & A-MLR $\left(\mathrm{g} \mathrm{s}^{-1}\right)$ & $\begin{array}{l}\mathrm{CO} / \mathrm{CO}_{2} \\
\left(\mathrm{~kg} \mathrm{~kg}^{-1}\right)\end{array}$ & $\begin{array}{r}\text { Char residue yield } \\
\text { (\%) }\end{array}$ \\
\hline $\mathrm{F}_{\text {Blank }}$ & 3 & 219.68 & 17.08 & 328.44 & 0.052 & 0.051 & 18.96 \\
\hline $\mathrm{F}_{3 \%}$ & 6 & 151.19 & 14.86 & 197.57 & 0.039 & 0.028 & 26.80 \\
\hline $\mathrm{F}_{3.5 \%}$ & 7 & 145.52 & 12.98 & 197.89 & 0.034 & 0.021 & 31.51 \\
\hline
\end{tabular}
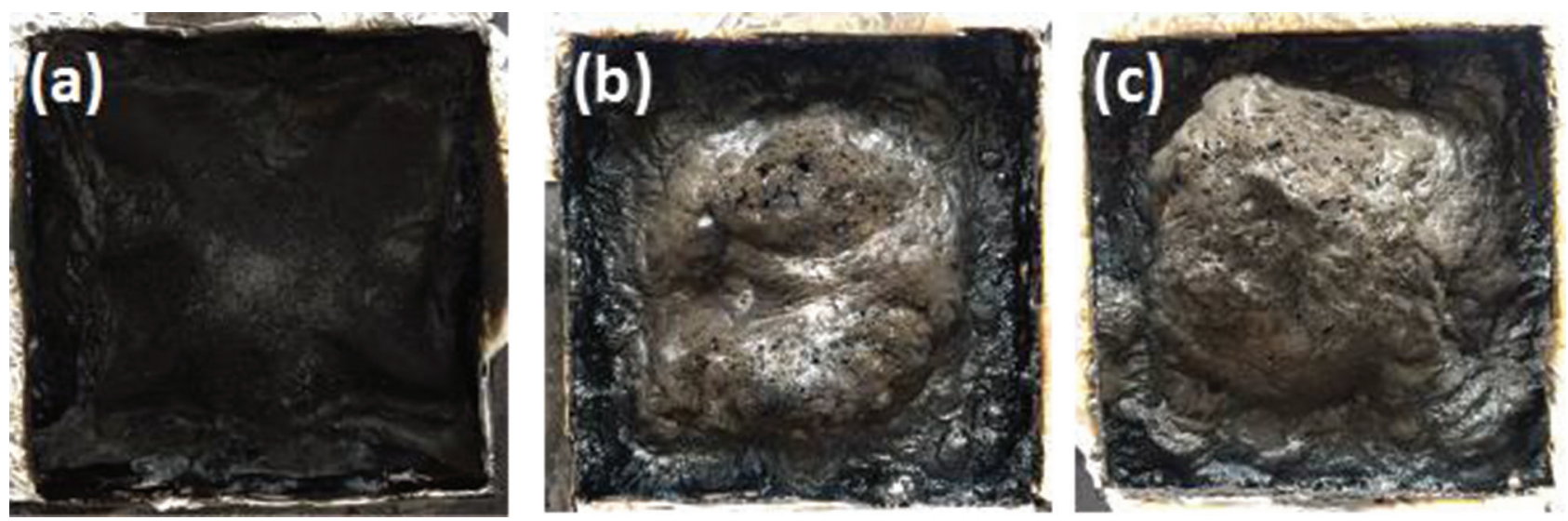

Figure 2: The digital photos for the residues of (a) $\mathrm{F}_{\text {Blank }}$, (b) $\mathrm{F}_{3 \%}$ and (c) $\mathrm{F}_{3.5 \%}$ after CONE test.

to $31.51 \%$ (flame retarded RPUF with $3.5 \mathrm{wt} \% \mathrm{P}$ ), which might be attributed to the transformation towards polyphosphoric acid for $\mathrm{P}$ groups in ODOPM-CYC.

A-MLR represents the thermal cracking, volatilization and combustion of materials under a certain fire intensity. According to Table 2, the A-MLR value reduced from 0.052 to $0.034 \mathrm{~g} \mathrm{~s}^{-1}$, indicating that much more char residues were formed in flame retarded RPUFs (confirmed by Figure 2). What is more, it can be found that the $\mathrm{CO} / \mathrm{CO}_{2}$ ratios for flame retarded RPUF with 3 and $3.5 \mathrm{wt} \% \mathrm{P}$ were 0.028 and 0.021 , which were significantly lower than that of neat RPUF (0.051), further revealing the effective smoke suppression of ODOPM-CYC for RPUF.

\subsubsection{Thermal stability}

To investigate the effect of ODOPM-CYC on the thermal stability of RPUF, TGA and differential thermogravimetry (DTG) were carried out and the results were presented in Figure 4. As shown in Table 3, the onset degradation temperature $\left(\mathrm{T}_{\text {onset }}\right)$ of flame retarded RPUF with $3 \mathrm{wt} \% \mathrm{P}$ was observed to show a slight increase in comparison with neat RPUF, which might be attributed to the high thermal stability of aromatic structure in ODOPM-CYC. Figure 4 showed the temperature range of significant weight loss narrowed when ODOPM-CYC was incorporated and the maximum decomposition temperature $\left(\mathrm{T}_{\max }\right)$ also 

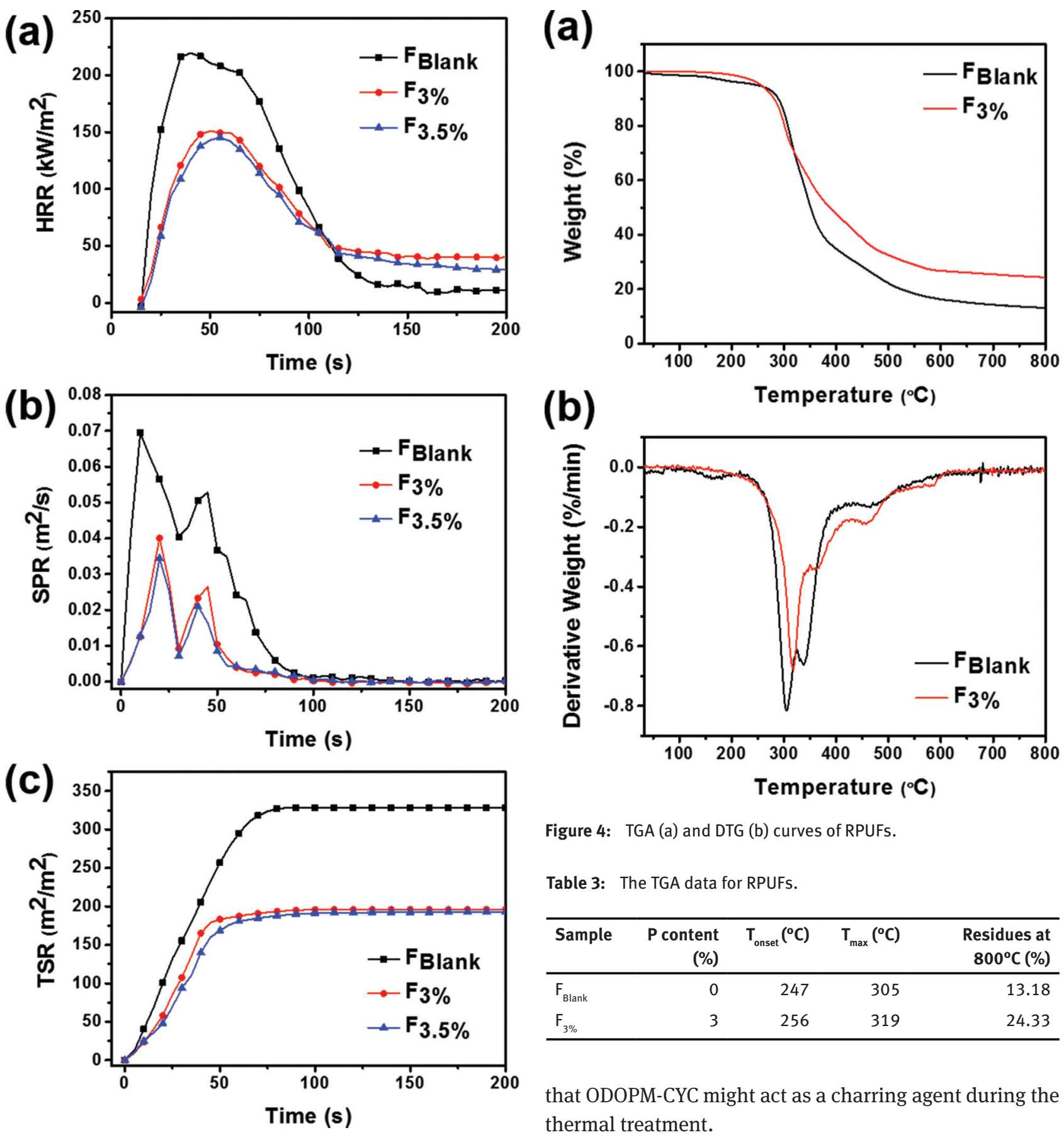

Figure 4: TGA (a) and DTG (b) curves of RPUFs.

Table 3: The TGA data for RPUFs.

\begin{tabular}{lrrrr}
\hline Sample & $\begin{array}{r}\mathrm{P} \text { content } \\
(\%)\end{array}$ & $\mathrm{T}_{\text {onset }}\left({ }^{\circ} \mathrm{C}\right)$ & $\mathrm{T}_{\max }\left({ }^{\circ} \mathrm{C}\right)$ & $\begin{array}{r}\text { Residues at } \\
800^{\circ} \mathrm{C}(\%)\end{array}$ \\
\hline $\mathrm{F}_{\text {Blank }}$ & 0 & 247 & 305 & 13.18 \\
$\mathrm{~F}_{3 \%}$ & 3 & 256 & 319 & 24.33 \\
\hline
\end{tabular}

that ODOPM-CYC might act as a charring agent during the thermal treatment.

Figure 3: (a) The heat release rate curves for RPUFs; The SPR (b) and TSR (c) curves for RPUFs.

increased from $305^{\circ} \mathrm{C}$ to $319^{\circ} \mathrm{C}$ in comparison with neat RPUF. Some radical species such as $\mathrm{PO}, \mathrm{PO}_{2}$ and $\mathrm{POCH}_{3}$ were reported to be released with the decomposition of DOPO and its derivatives, which could react with $\cdot \mathrm{H}$ and $\cdot \mathrm{OH}$ radicals to lower the heat production amount and improve the thermal stability (28). In addition, flame retarded RPUF with $3 \mathrm{wt} \% \mathrm{P}$ exhibited higher residues (24.33\%) than neat RPUF (13.18\%) at $800^{\circ} \mathrm{C}$, indicating

\subsubsection{Physical and mechanical properties}

The mechanical property is an important parameter of RPUF, which greatly depends on its cell structure and density (collected in Table 1). The cell structures of foams were observed by SEM (shown in Figure 6). The foam density showed a slight increase with the increasing addition of ODOPM-CYC, which was probably due to the decrease of cell size and the embedding of flame retardant particles into cell wall. 

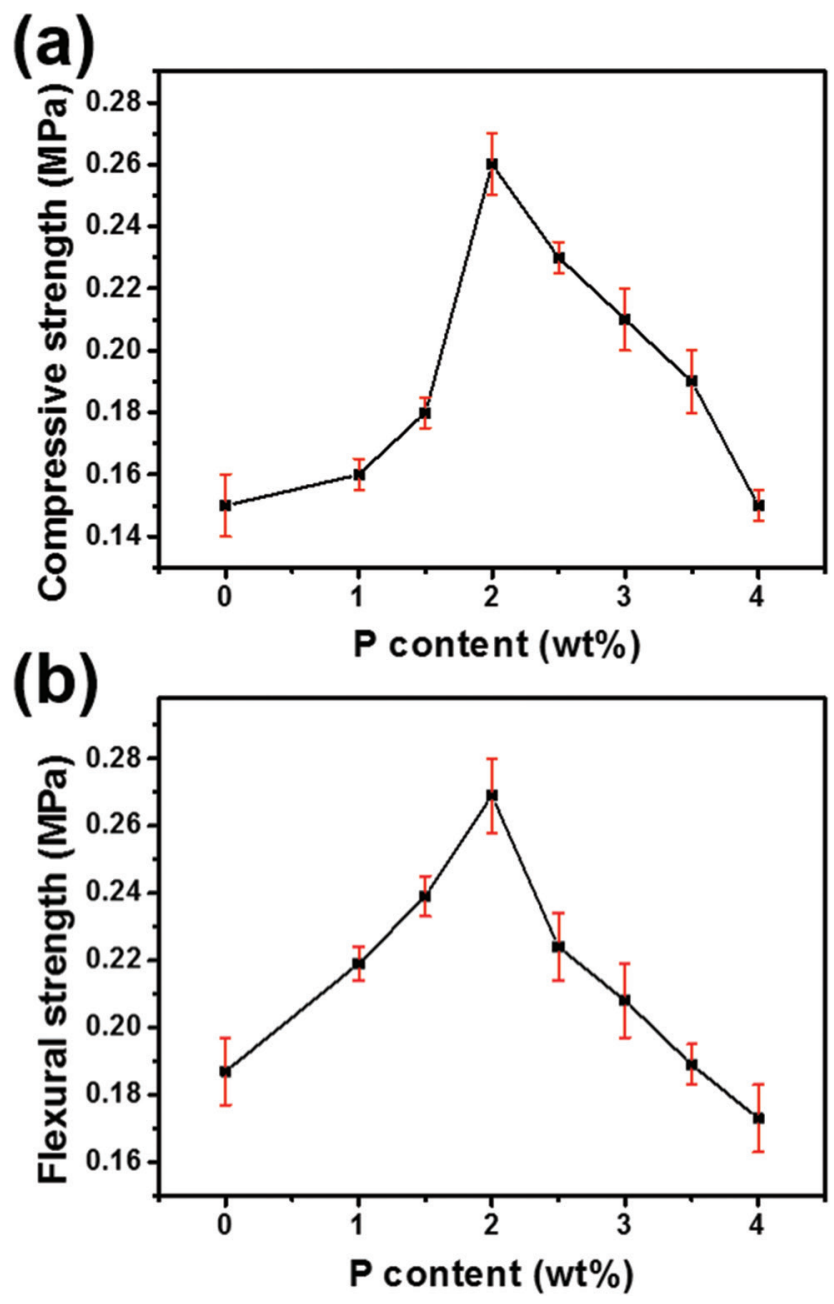

Figure 5: The compressive (a) and flexural (b) strength of RPUFs.
As seen from Figure 5, the compressive strength increased with rising $\mathrm{P}$ content at first and reached the peak value at $0.26 \mathrm{MPa}$ with the addition of $2 \mathrm{wt} \% \mathrm{P}$, which was nearly double than that of neat RPUF (0.15 MPa). The flexural strength also increased from 0.187 to $0.269 \mathrm{MPa}$ under the same addition content. The improvement of mechanical properties might be attributed to the increase of foam density and negligible cell collapse or collision (shown in Table 1 and Figure 6). The results indicated that ODOPM-CYC possessed good miscibility with RPUF. However, when the addition of $\mathrm{P}$ was beyond $3 \mathrm{wt} \%$, it can be seen that the integrity of the cell was undermined and cell size distribution became wider, thus the mechanical properties decreased correspondingly.

\subsubsection{Thermal conductivity}

For insulation materials, a low thermal conductivity is of great necessity. According to the test results listed in Table 1 , there is no significant increase in thermal conductivity values after the incorporation of ODOPM-CYC. The slight increase might be attributed to the decrease of closed cell content and the formation of airflow passage caused by the collapse of cells (shown in Figure 6).

\section{Conclusions}

In this study, an intumescent halogen-free flame retardant ODOPM-CYC was successfully prepared and applied to
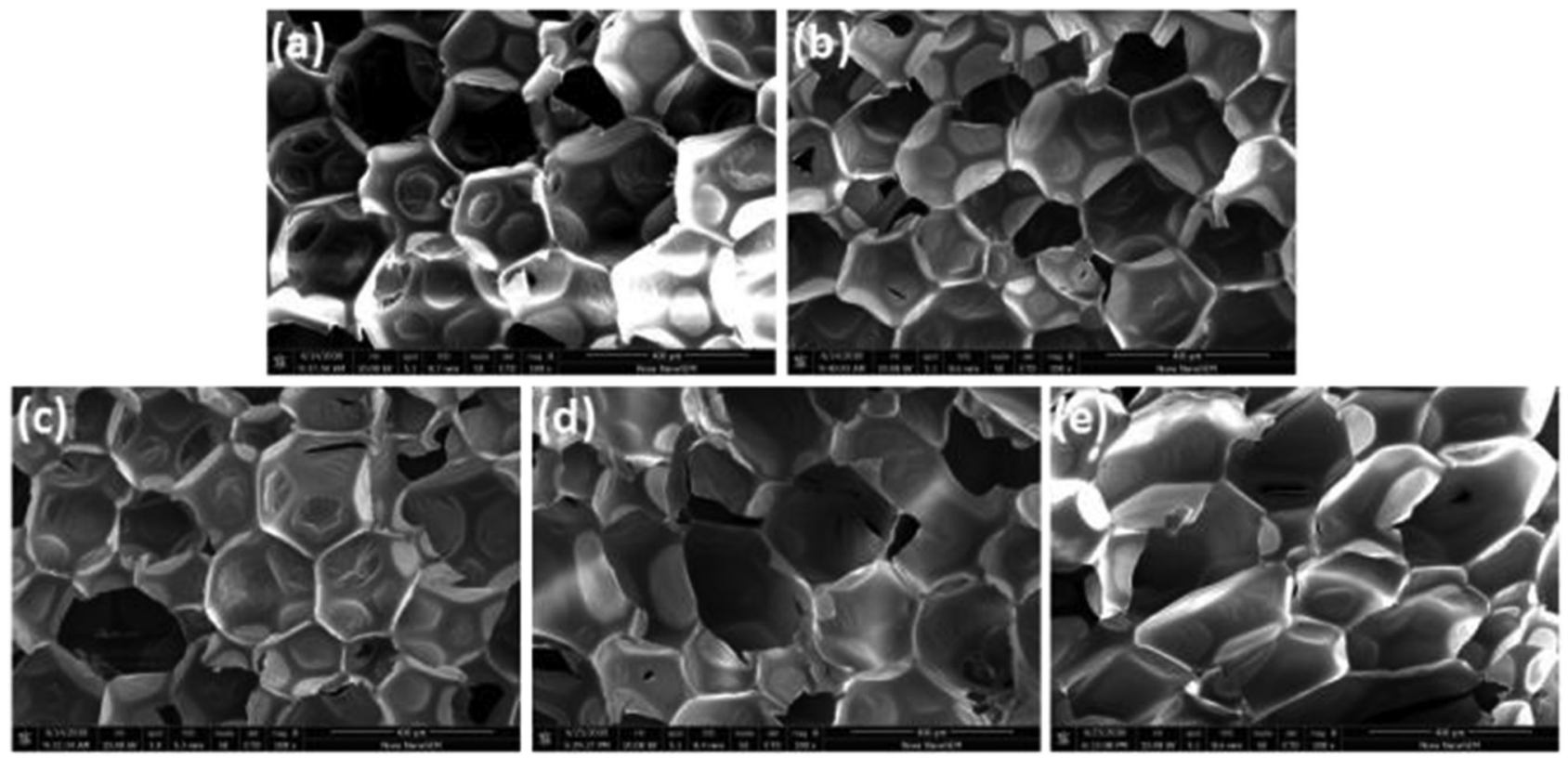

Figure 6: SEM images of RPUFs: (a) $\mathrm{F}_{\text {Blank }}$, (b) $\mathrm{F}_{1 \%}$, (c) $\mathrm{F}_{2 \%}$, (d) $\mathrm{F}_{3 \%}$ and (e) $\mathrm{F}_{4 \%}$. The magnification of all images, $100 \times$. 
RPUFs. It has been confirmed that ODOPM-CYC displayed excellent flame retardant properties in RPUF. The flame retarded RPUF acquired a LOI value of $26 \%$ and achieved UL-94 V-0 rating with the P content of $3 \mathrm{wt} \%$. Meanwhile, a suppression effect on smoke and heat was also observed. Compared with neat RPUF, the PHRR, THR, SPR and TSR of foams containing ODOPM-CYC all decreased, which is due to the barrier effect of the formed intumescent char. Furthermore, when P content was less than $3 \mathrm{wt} \%$, the foam cell showed slight collapse or collision in the presence of ODOPM-CYC, thus resulting in the promotion of physical mechanical. Besides, the incorporation of ODOPM-CYC improved the thermal stability of RPUF along with negligible change on its thermal conductivity. This study implies that ODOPM-CYC is a promising flame retardant for RPUF.

Acknowledgments: This work was supported by the National Natural Science Foundation of China (No. U1205114).

\section{References}

1. Ciecierska E., Jurczyk-Kowalska M., Bazarnik P., Kowalski M., Krauze S., Lewandowska M., The influence of carbon fillers on the thermal properties of polyurethane foam. J Therm Anal Calorin, 2016, 123, 283-291.

2. Ding H., Xia C., Wang J., Wang C., Chu F., Inherently flameretardant flexible bio-based polyurethane sealant with phosphorus and nitrogen-containing polyurethane prepolymer. J Mater Sci, 2016, 51, 5008-5018.

3. Zhao Q., Chen C., Fan R., Yuan Y., Xing Y., Ma X., Halogen-free flame-retardant rigid polyurethane foam with a nitrogenphosphorus flame retardant. J Fire Sci, 2017, 35, 99-117.

4. Li A., Yang D.D., Li H.N., Jiang C.L., Liang J.Z., Flame-retardant and mechanical properties of rigid polyurethane foam/MRP/ $\mathrm{Mg}(\mathrm{OH})_{2} / \mathrm{GF} / \mathrm{HGB}$ composites. Appl Polym Sci, 2018, 135, 46551.

5. Titelman G.I., Gonen Y., Keidar Y., Bron S., Discolouration of polypropylene-based compounds containing magnesium hydroxide. Polym Degrad Stab, 2002, 77, 345-352.

6. Lu S.Y., Hamerton I., Recent developments in the chemistry of halogen-free flame retardant polymers. Prog Polym Sci, 2002, 27, 1661-1712.

7. Wang S.X., Zhao H.B., Rao W.H., Huang S.C., Wang T., Liao W., et al., Inherently flame-retardant rigid polyurethane foams with excellent thermal insulation and mechanical properties. Polymer, 2018, 153, 616-626.

8. Rao W.H., Xu H.X., Xu Y.J., Qi M., Liao W., Xu S., et al., Persistently flame-retardant flexible polyurethane foams by a novel phosphorus-containing polyol. Chem Eng J, 2018, 343, 198-206.

9. Guo W., Wang X., Zhang P., Liu J., Song L., Hu Y., Nano-fibrillated cellulose-hydroxyapatite based composite foams with excellent fire resistance. Carbohydr Polym, 2018, 195, 71-78.
10. Lu W., Li Q., Zhang Y., Yu H., Hirose S., Hatakeyama H., Jin Z., Lignosulfonate/APP IFR and its flame retardancy in lignosulfonate-based rigid polyurethane foams. J Wood Sci, 2018, 64, 287-293.

11. Xu W.Z., Liu L., Wang S.Q., Hu Y., Synergistic effect of expandable graphite and aluminum hypophosphite on flame-retardant properties of rigid polyurethane foam. Appl Polym Sci, 2015, 132, 42842.

12. Salmeia K.A., Gaan S., An overview of some recent advances in DOPO-derivatives: Chemistry and flame retardant applications. Polym Degrad Stab, 2015, 113, 119-134.

13. Yang L., Xu L., Tao Z., Palladium-catalyzed arylation of 9,10-Dihydro-9-oxa-10-phosphaphenanthrene-10-oxide (DOPO) with Halogen-Substituted Phenols. Phosphorus Sulfur Silicon Relat Elem, 2009, 184, 3175-3181.

14. Vasiljević J., Jerman I., Jakša G., Alongi J., Malucelli G., Zorko M., et al., Functionalization of cellulose fibres with DOPO-polysilsesquioxane flame retardant nanocoating. Cellulose, 2015, 22, 1893-1910.

15. Xie C., Zeng B., Gao H., Xu Y., Luo W., Liu X., Dai L., Improving thermal and flame-retardant properties of epoxy resins by $a$ novel reactive phosphorous-containing curing agent. Polym Eng Sci, 2014, 54, 1192-1200.

16. Ciesielski M., Schäfer A., Döring M., Novel efficient DOPO-based flame-retardants for PWB relevant epoxy resins with high glass transition temperatures. Polym Adv Technol, 2010, 19, 507-515.

17. Wang X., Hu Y., Song L., Yang H., Xing W. Lu H., Synthesis and characterization of a DOPO-substitued organophosphorus oligomer and its application in flame retardant epoxy resins. Prog Org Coat, 2011, 71, 72-82.

18. Huo S., Wang J., Yang S., Wang J., Zhang B., Zhang B., et al., Synthesis of a novel phosphorus-nitrogen type flame retardant composed of maleimide, triazine-trione, and phosphaphenanthrene and its flame retardant effect on epoxy resin. Polym Degrad Stab, 2016, 131, 106-113.

19. Qian L., Qiu Y., Liu J., Xin F., Chen Y., The flame retardant group-synergistic-effect of a phosphaphenanthrene and triazine double-group compound in epoxy resin. J Appl Polym Sci, 2014, 131, 1082-1090.

20. Bai Z., Song L., Hu Y., Yuen R.K.K., Preparation, flame retardancy, and thermal degradation of unsaturated polyester resin modified with a novel phosphorus containing acrylate. Ind Eng Chem Res, 2013, 52, 12855-12864.

21. Zhang C., Liu S.M., Zhao J.Q., Huang J.Y., Synthesis and properties of a modified unsaturated polyester resin with phosphoruscontaining pendant groups. Polym Bull, 2013, 70, 1097-1111.

22. Gaan S., Liang S., Mispreuve H., Perler H., Naescher R., Neisius M., Flame retardant flexible polyurethane foams from novel DOPO-phosphonamidate additives. Polym Degrad Stab, 2015, 113, 180-188.

23. Gaan S., Neisius M., Cuchere O., Liang S., Mispreuve H., Flame retardant polyurethanes based on novel phosphonamidate additives. Fire Safety Sci, 2014, 11, 821-831.

24. König A., Kroke E., Flame retardancy working mechanism of methyl-DOPO and MPPP in flexible polyurethane foam. Fire Mater, 2012, 36, 1-15.

25. Liu Y., He J., Yang R., The preparation and properties of flameretardant polyisocyanurate-polyurethane foams based on two DOPO derivatives. J Fire Sci, 2016, 34, 431-444. 
26. König A., Kroke E., Methyl-DOPO: a new flame retardant for flexible polyurethane foam. Polym Adv Technol, 2011, 22, 5-13.

27. Wang P., Yang F., Li L., Cai Z., Flame retardancy and mechanical properties of epoxy thermosets modified with a novel DOPO-based oligomer. Polym Degrad Stab, 2016, 129, 156-167.

28. Rakotomalala M., Wagner S., Döring M., Recent developments in halogen free flame retardants for epoxy resins for electrical and electronic applications. Materials, 2010, 3, 4300-4327.

29. Li R.M., Deng C., Deng C.L., Dong L.P., Di H.W., Wang Y.Z., An efficient method to improve simultaneously the water resistance, flame retardancy and mechanical properties of POE intumescent flame-retardant systems. RSC Adv, 2015, 5, 16328-16339.

30. Deng C.L., Du S.L., Zhao J., Shen Z.Q., Deng C., Wang Y.Z., An intumescent flame retardant polypropylene system with simultaneously improved flame retardancy and water resistance. Polym Degrad Stab, 2014, 108, 97-107.

31. Guan Y.H., Huang J.Q., Yang J.C., Shao Z.B., Wang Y.Z., An effective way to flame-retard biocomposite with ethanolamine modified ammonium polyphosphate and its flame retardant mechanisms. Ind Eng Chem Res, 2015, 54, 3524-3531.

32. Shieh J.Y., Wang C.S., Synthesis of novel flame retardant epoxy hardeners and properties of cured products. Polymer, 2001, 42, 7617-7625.

33. Yang S., Wang J., Huo S., Wang M., Cheng L., Synthesis of a phosphorus/nitrogen-containing additive with multifunctional groups and its flame-retardant effect in epoxy resin. Ind Eng Chem Res, 2015, 54, 7777-7786.

34. Chang S.C., Condon B., Graves E., Uchimiya M., Fortier C., Easson M., et al., Flame retardant properties of triazine phosphonates derivative with cotton fabric. Fiber Polym, 2011, 12, 334-339.

35. Xu D.M., Ding F., Hao J.W., Jian-Xin D.U., Preparation of modified expandable graphite and its flame retardant application in rigid polyurethane foam. Chem J Chinese U, 2013, 34, 2674-2680.

36. Brehme S., Schartel B., Goebbels J., Fischer O., Pospiech D., Bykov Y., et al., Phosphorus polyester versus aluminium phosphinate in poly(butylene terephthalate) (PBT): Flame retardancy performance and mechanisms. Polym Degrad Stab, 2011, 96, 875-884.

37. Hoang D.Q., Synthesis and applications of biscyclic phosphorus flame retardants. Polym Degrad Stab, 2008, 93, 36-42. 